\title{
Relationship between mutations in parC and gyrA of clinical isolates of Streptococcus pneumoniae and resistance to ciprofloxacin and grepafloxacin
}

\author{
B. A. STEWART, A. P. JOHNSON* and N. WOODFORD* \\ Microbiology and Virology Clinical Group, Royal Hospitals NHS Trust, 37 Ashfield Street, London E1 $1 B B$ and \\ *Antibiotic Resistance Monitoring and Reference Laboratory, Central Public Health Laboratory, 61 Colindale \\ Avenue, London NW9 5 HT
}

\begin{abstract}
The mechanisms of resistance to ciprofloxacin and grepafloxacin were studied in 54 clinical isolates of Streptococcus pneumoniae. Restriction fragment length polymorphism analysis following HinfI digestion was used with DNA sequencing to identify mutations in the quinolone resistance-determining regions (QRDRs) of the parC and gyrA genes. Ciprofloxacin MICs up to $16 \mathrm{mg} / \mathrm{L}$ were not associated with mutations to these genes in approximately half of the isolates. In other isolates, moderate levels of ciprofloxacin resistance (MIC $8-16 \mathrm{mg} / \mathrm{L}$ ) were associated with an alteration of ParC, most commonly entailing replacement of serine-79 by phenylalanine. High-level ciprofloxacin resistance (MIC $32-128 \mathrm{mg} / \mathrm{L}$ ) entailed the additional mutation of GyrA with substitution of serine-83 by phenylalanine. Grepafloxacin MICs $>4 \mathrm{mg} / \mathrm{L}$ were associated with this GyrA mutation alone; no relationship was detected between grepafloxacin MICs and mutation of the QRDR of parC.
\end{abstract}

\section{Introduction}

Resistance to available antibiotics is increasing among isolates of Streptococcus pneumoniae [1], underlining a need for novel agents. Fluoroquinolones, such as ciprofloxacin and ofloxacin, have been regarded as poor choices for the treatment of pneumococcal infections because the MIC90s for sensitive strains cluster around the recommended breakpoints for susceptibility (1-4 mg/L) [2,3]. However, several new fluoroquinolones have 4-8-fold greater activity than ciprofloxacin against pneumococci $[2,3]$. In a previous study of one such agent - grepafloxacin MICs for $98 \%$ of 260 clinical isolates of $S$. pneumoniae were $\leqslant 0.03-0.5 \mathrm{mg} / \mathrm{L}$ and were independent of penicillin MICs [4].

Some S. pneumoniae strains have increased resistance to fluoroquinolones. Mechanistic studies on this topic have centred upon ciprofloxacin and have mostly used small numbers of mutants selected step-wise for resistance in vitro, or laboratory transformants derived from wild-type strains [5-8]. Low-level ciprofloxacin resistance

Received 17 March 1999; accepted 12 April 1999.

Corresponding author: Dr B. A. Stewart. Present address: Department of Microbiology, East Surrey Hospital, Surrey RH1 5RH.
(MIC $\leqslant 16 \mathrm{mg} / \mathrm{L}$ ) can be conferred by mutation within the quinolone resistance-determining region (QRDR) of $\operatorname{parC}$. This gene encodes the ParC subunit of DNA topoisomerase IV, which is the primary target of ciprofloxacin in pneumococci. Mutation most commonly entails substitution of serine-79 by tyrosine or phenylalanine [5-7]. High-level resistance (MIC $\geqslant 32 \mathrm{mg} / \mathrm{L}$ ) requires additional mutation within the analogous $\mathrm{QRDR}$ region of GyrA, particularly at the position equivalent to serine-83 of Escherichia coli [5-7].

This study investigated the effect of ciprofloxacin resistance on the activity of grepafloxacin in clinical isolates of $S$. pneumoniae. Mechanisms of resistance were investigated to determine whether the mutations described in laboratory mutants were also responsible for resistance among clinical isolates.

\section{Materials and methods}

\section{Isolates}

Fifty-four clinical isolates of $S$. pneumoniae with various levels of ciprofloxacin resistance were selected from isolates referred to the Antibiotic Resistance Monitoring and Reference Laboratory (ARMRL) at the Central Public Health Laboratory in London from diverse locations throughout the UK. The isolates were 
heterogeneous with respect to serotype and antibiogram. They had been stored at $-70^{\circ} \mathrm{C}$.

\section{MIC tests}

MICs of ciprofloxacin (Sigma) and grepafloxacin (GlaxoWellcome, Stevenage) were determined by an agar-incorporation method on Diagnostic Sensitivity Test (DST) agar (Oxoid) containing lysed horse blood (TCS Microbiology, Buckingham) 5\% with an inoculum of $10^{4} \mathrm{cfu} / \mathrm{spot}$. The concentration ranges of both antibiotics were $256-0.5 \mathrm{mg} / \mathrm{L}$. MICs were determined in duplicate and any isolate displaying greater than two-fold variation between readings was re-tested with an E-test strip (AB Biodisk, Solna, Sweden).

\section{PCR of gyrA and parC}

A 382-bp region of $g y r A$, comprising the bases corresponding to amino acids 46-172 of the GyrA subunit of the DNA gyrase of $E$. coli, was amplified with the primers and conditions described previously [5].

Similarly, a 366-bp fragment of parC was amplified, corresponding to amino acids 35-157 [5]. By analogy to $E$. coli, the QRDR of GyrA spans amino acids 67106 , and this is the region where homology with ParC is greatest [6].

\section{Restriction fragment length polymorphism (RFLP) analysis}

The PCR products of gyrA and parC were digested with HinfI (Boehringer Mannheim, Lewes) to screen for mutations at positions serine-83 of GyrA and serine79 of ParC [5]. These are the sites where modification is most often reported to confer fluoroquinolone resistance in laboratory pneumococci [5-7].

\section{DNA sequence analysis}

Twenty-two isolates were selected for DNA sequencing on the basis of MIC data and RFLP analysis. The gyrA and $\operatorname{par} C$ products were purified with a Recovery Kit (Hybaid, Teddington) and dye terminator cycle sequencing was performed with an ABI PRISM Ready Reaction Kit (Applied Biosystems, Perkin-Elmer, Warrington) with the same primers as for the original PCR reactions. Each amplicon was sequenced in both directions. Sequencing reactions had a final volume of $20 \mu \mathrm{l}$ containing 50-80 ng of template DNA, $5 \mathrm{pmol}$ of primer and $8 \mu \mathrm{l}$ of 'Ready Reaction' mix. Cycling conditions were $95^{\circ} \mathrm{C}$ for $1 \mathrm{~min}$ for one cycle, followed by 25 cycles of $96^{\circ} \mathrm{C}$ for $30 \mathrm{~s}, 50^{\circ} \mathrm{C}$ for $15 \mathrm{~s}$ and $60^{\circ} \mathrm{C}$ for $4 \mathrm{~min}$. A ramp rate of $1^{\circ} \mathrm{C} / \mathrm{s}$ was used throughout.

Sequences were determined with either ABI PRISM 310 or ABI PRISM 377 DNA Sequencers (PerkinElmer) and analysed with the ABI PRISM Sequence Navigator, version 1.0.1, 1994 (Perkin-Elmer). The sequences were compared with the wild-type sequences of $S$. pneumoniae (GenBank accession numbers: X95718 for gyrA and X95717 for parC) and mutations were defined by the presence of a complementary alteration of the base at the same site in both DNA strands.

\section{Results}

The distribution of MICs of ciprofloxacin and grepafloxacin are shown in Fig. 1, which also illustrates the approximately linear relationship between the MICs of the two agents. For most isolates the grepafloxacin MIC was 4-8-fold lower than that of ciprofloxacin. This linear relationship between ciprofloxacin and grepafloxacin MICs contrasts with the stepped relationship seen between ciprofloxacin and sparfloxacin, where strains with ciprofloxacin MICs $<32 \mathrm{mg} / \mathrm{L}$ remained fully susceptible to sparfloxacin, whereas those with ciprofloxacin $\mathrm{MICs} \geqslant 32 \mathrm{mg} / \mathrm{L}$ were strongly cross-resistant [8].

The most frequent mutation observed was an alteration of ParC, with lysine-137 replaced by asparagine (Table 1). The presence of this mutation did not correlate with the MICs of ciprofloxacin or grepafloxacin and, in agreement with previous authors [6], it is concluded that it was not involved in fluoroquinolone resistance.

RFLP analysis of the gyrA and parC amplicons from 11 isolates with low-level ciprofloxacin resistance (MIC 2-4 mg/L; grepafloxacin MIC range $0.5-$ $1 \mathrm{mg} / \mathrm{L}$ ) indicated that none had mutations at serine83 of GyrA or serine-79 of ParC. Both amplicons were sequenced from two isolates of this group and no mutations (other than at lysine-137 in one isolate) were detected within the QRDRs of either gene.

RFLP analysis of the amplicons from 26 moderately ciprofloxacin-resistant isolates (MIC $8-16 \mathrm{mg} / \mathrm{L}$; grepafloxacin MIC range $0.5-4 \mathrm{mg} / \mathrm{L}$ ) demonstrated that half possessed a mutation at serine-79 of $\mathrm{ParC}$, and sequence analysis of the amplicons of three isolates revealed alterations to phenylalanine. Twelve isolates with moderate ciprofloxacin resistance $(46 \%)$ lacked this mutation. The amplicons of six of these were sequenced: two were found to possess alternative mutations of parC, changing aspartate-83 to tyrosine and four had no detectable mutations of ParC. None of the gyrA amplicons of these nine isolates had detectable mutations. In contrast, the remaining isolate with moderate ciprofloxacin resistance ( $\mathrm{MIC}=$ $16 \mathrm{mg} / \mathrm{L}$; grepafloxacin $\mathrm{MIC}=4 \mathrm{mg} / \mathrm{L}$ ) possessed mutation at serine-83 of GyrA, but no mutation at serine-79 of ParC.

Among the 17 isolates with high-level ciprofloxacin resistance (MIC $32-128 \mathrm{mg} / \mathrm{L}$; grepafloxacin MIC 


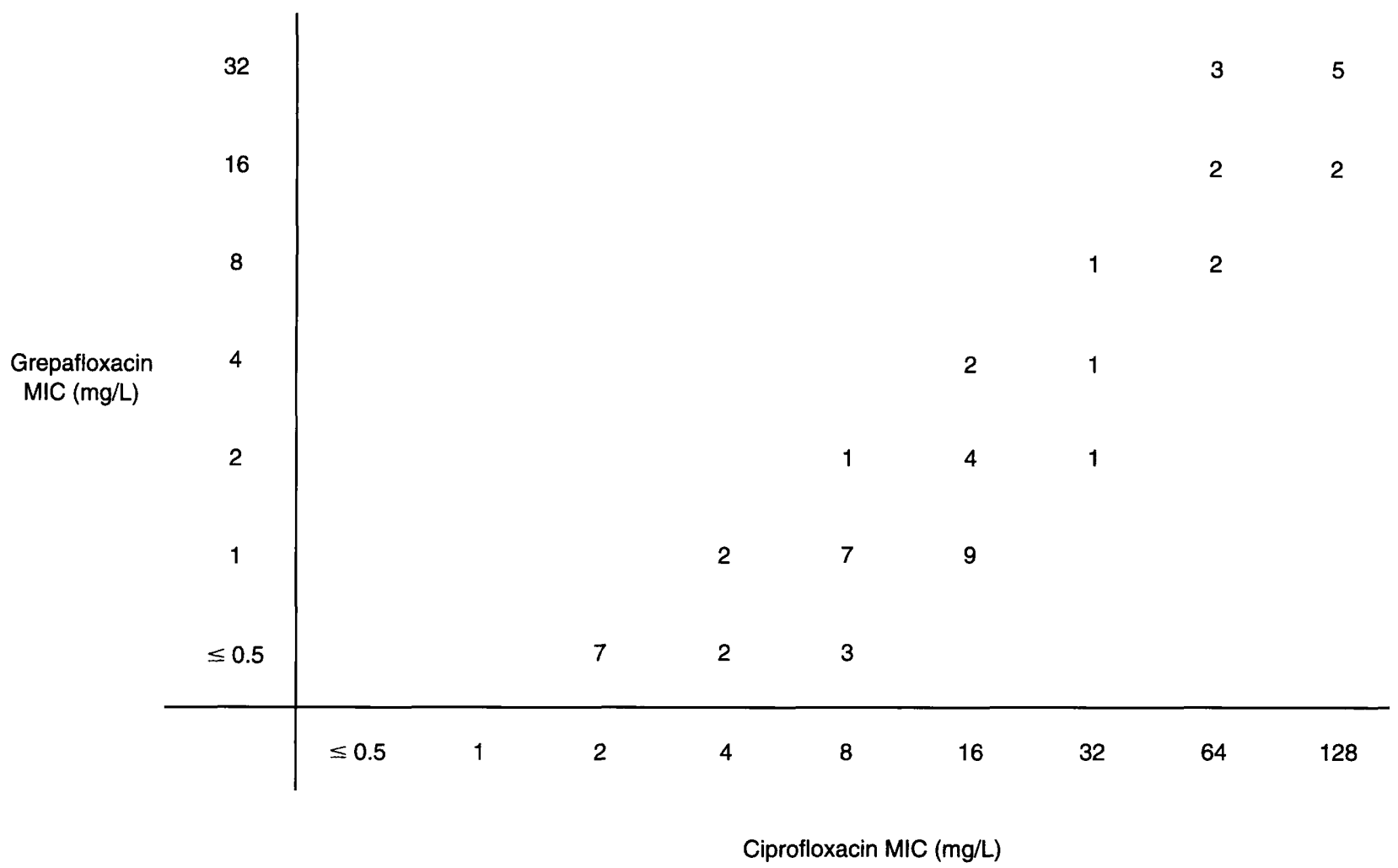

Fig. 1. Scatter diagram of ciprofloxacin and grepafloxacin MICs for 54 clinical isolates of S. pneumoniae: values indicate the number of isolates with each combination of MICs.

Table 1. Mutations in the quinolone resistance-determining regions of ParC and GyrA of 22 clinical isolates of $S$. pneumoniae

\begin{tabular}{|c|c|c|c|c|c|c|}
\hline \multirow[b]{2}{*}{ Strain no. } & \multicolumn{2}{|c|}{$\mathrm{MIC}(\mathrm{mg} / \mathrm{L})$} & \multicolumn{3}{|c|}{ ParC } & \multirow{2}{*}{$\begin{array}{l}\text { GyrA } \\
\text { (pos 83) }\end{array}$} \\
\hline & Ciprofloxacin & Grepafloxacin & pos 137 & pos 79 & pos 83 & \\
\hline $98 / 0140$ & 2 & 0.5 & - & - & - & - \\
\hline $98 / 0141$ & 2 & 0.5 & Lys $\rightarrow$ Asn & - & - & - \\
\hline $97 / 0647$ & 8 & 1 & Lys $\rightarrow$ Asn & $\mathrm{Ser} \rightarrow \mathrm{Phe}$ & - & - \\
\hline $98 / 0050$ & 8 & 1 & - & - & - & - \\
\hline $97 / 3176$ & 16 & 1 & - & - & - & - \\
\hline $97 / 2942$ & 16 & 1 & Lys $\rightarrow$ Asn & - & - & - \\
\hline $97 / 3612$ & 16 & 1 & Lys $\rightarrow$ Asn & $\mathrm{Ser} \rightarrow \mathrm{Phe}$ & - & - \\
\hline $97 / 3735$ & 16 & 1 & Lys $\rightarrow$ Asn & $\mathrm{Ser} \rightarrow \mathrm{Phe}$ & - & - \\
\hline $98 / 0030$ & 16 & 1 & Lys $\rightarrow$ Asn & - & - & - \\
\hline $98 / 0096$ & 16 & 2 & Lys $\rightarrow$ Asn & - & Asp $\rightarrow \mathrm{Tyr}$ & - \\
\hline $97 / 0486$ & 16 & 4 & Lys $\rightarrow$ Asn & - & Asp $\rightarrow$ Tyr & - \\
\hline $97 / 2662$ & 32 & 8 & - & - & - & Ser $\rightarrow$ Phe \\
\hline $96 / 2105$ & 64 & 8 & Lys $\rightarrow$ Asn & - & - & Ser $\rightarrow$ Phe \\
\hline $96 / 0419$ & 64 & 16 & - & - & Asp $\rightarrow$ Tyr & Ser $\rightarrow$ Phe \\
\hline $98 / 0156$ & 64 & 32 & Lys $\rightarrow$ Asn & - & $\mathrm{Asp} \rightarrow \mathrm{Gly}$ & $\mathrm{Ser} \rightarrow \mathrm{Phe}$ \\
\hline $97 / 1796$ & 64 & 32 & - & $\mathrm{Ser} \rightarrow \mathrm{Phe}$ & - & $\mathrm{Ser} \rightarrow \mathrm{Phe}$ \\
\hline $96 / 3024$ & 128 & 16 & Lys $\rightarrow$ Asn & $\mathrm{Ser} \rightarrow \mathrm{Phe}$ & - & $\mathrm{Ser} \rightarrow \mathrm{Phe}$ \\
\hline $97 / 0446$ & 128 & 32 & Lys $\rightarrow$ Asn & $\mathrm{Ser} \rightarrow \mathrm{Phe}$ & - & Ser $\rightarrow$ Phe \\
\hline $97 / 0594$ & 128 & 32 & Lys $\rightarrow$ Asn & $\mathrm{Ser} \rightarrow$ Phe & - & Ser $\rightarrow$ Phe \\
\hline $97 / 0961$ & 128 & 32 & Lys $\rightarrow$ Asn & $\mathrm{Ser} \rightarrow \mathrm{Phe}$ & - & Ser $\rightarrow$ Phe \\
\hline $97 / 1163$ & 128 & 32 & Lys $\rightarrow$ Asn & $\mathrm{Ser} \rightarrow$ Phe & - & Ser $\rightarrow$ Phe \\
\hline $97 / 1282$ & 128 & 32 & Lys $\rightarrow$ Asn & $\mathrm{Ser} \rightarrow \mathrm{Tyr}$ & - & $\mathrm{Ser} \rightarrow \mathrm{Phe}$ \\
\hline
\end{tabular}

range $2-32 \mathrm{mg} / \mathrm{L}$ ), four were also observed to possess mutation at serine-83 of GyrA in the absence of mutation at serine-79 of ParC. Sequence analysis of their gyrA and parC amplicons revealed replacement of serine-83 of GyrA by phenylalanine in all four isolates, with additional substitution of aspartate- 83 of
ParC by tyrosine or glycine in two. Eleven other isolates with high-level resistance $(65 \%)$ yielded parC and gyrA amplicons which were insusceptible to digestion with Hinfl, indicating mutations at both serine- 79 and serine- 83 , respectively. Sequence analysis of the amplicons of seven of these 11 isolates revealed 
replacement of serine-79 of ParC by either phenylalanine or tyrosine, and replacement of serine-83 of GyrA by phenylalanine. No additional mutations were observed.

RFLP analysis of the remaining two isolates with highlevel resistance indicated the sole presence of mutations at serine-79 of ParC, without the additional mutations of GyrA [5-7]. Amplicons from these isolates were not sequenced, but may have possessed the only other mutation of GyrA described to date, glutamine- 87 to lysine $[5,7,8]$.

In contrast to ciprofloxacin, isolates with grepafloxacin MICs $\geqslant 8 \mathrm{mg} / \mathrm{L}$ were associated with mutation of GyrA at serine-83 alone. No relationship was seen between the level of grepafloxacin MIC and the presence or absence of mutations of parC amplicons.

\section{Discussion}

These findings for quinolone-resistant clinical pneumococci largely correspond with observations for laboratory mutants [5-8]. Low levels of ciprofloxacin resistance among $S$. pneumoniae were apparently mediated by mechanisms other than mutation of the QRDR, perhaps by up-regulation of an active efflux system, analogous to the NorA pump of Staphylococcus aureus [9, 10]. Moderate levels of ciprofloxacin resistance also appeared to be mediated by such mechanisms in some isolates, but in others were associated with mutation of ParC. High-level resistance generally required additional mutation of GyrA, confirming the view that these subunits are the primary and secondary targets, respectively, of ciprofloxacin in clinical isolates of $S$. pneumoniae.

Nevertheless, the fact that two isolates with high-level ciprofloxacin resistance possessed mutations at Ser-83 of GyrA without detectable mutation of the QRDR region of ParC suggests that other mechanisms may be involved or that novel mutations may exist outside the ParC and GyrA regions sequenced. Mutation of gyrB has been reported in a single mutant with high-level resistance [5] and mutation in parE has also been observed recently at position aspartate-435, where it was associated with an eight-fold increase in the ciprofloxacin MIC for transformants (M. Chauvel et al., personal communication).

Currently, there are no susceptibility breakpoints recommended by the British Society for Antimicrobial Chemotherapy (BSAC) for grepafloxacin against $S$. pneumoniae, but recent recommendations by the National Committee for Clinical Laboratory Standards (NCCLS) define susceptibility as $\leqslant 0.5 \mathrm{mg} / \mathrm{L}$ (Anne M.
Harris, GlaxoWellcome, personal communication). On this basis, only 12 isolates $(22 \%)$ in the present study would be classified as susceptible. As these isolates were selected for the study, this situation does not reflect the true prevalence of resistance among clinical strains; nevertheless, ciprofloxacin resistance appears to be a marker of decreased susceptibility to grepafloxacin, and potentially to other new fluoroquinolones. Given that selection for ciprofloxacin-resistant pneumococci has been observed in vivo during therapy $[5,11]$, the efficacy of grepafloxacin is likely to be undermined by prior exposure of a strain to ciprofloxacin in the clinical setting.

This study was funded by a project grant from the British Society for Antimicrobial Chemotherapy and by GlaxoWellcome. We also thank Marina Warner of the ARMRL, Brigid Duke and Lucinda Hall of the Department of Medical Microbiology at St Bartholomew's and the Royal London School of Medicine and Dentistry, and Patricia Woodford of the Department of Medical Microbiology, Imperial College at St Mary's, London, for their help and assistance. Our thanks extend to Dr David Livermore for his helpful comments in the preparation of this manuscript.

\section{References}

1. Goldsmith CE, Moore JE, Murphy PG. Pneumococcal resistance in the UK. J Antimicrob Chemother 1997; 40 Suppl A: $\mathrm{S} 11-\mathrm{S} 18$.

2. Hoogkamp-Korstanje JAA. In-vitro activities of ciprofloxacin, levofloxacin, lomefloxacin, ofloxacin, pefloxacin, sparfloxacin and trovafloxacin against Gram-positive and Gram-negative pathogens from respiratory tract infections. $J$ Antimicrob Chemother 1997; 40: 427-431.

3. Eliopoulos GM. In-vitro activity of fluoroquinolones against Gram-positive bacteria. Drugs 1995; 49 Suppl 2: S48-S57.

4. Johnson AP, Warner M, Parsons T. Activity of grepafloxacin against respiratory isolates of Streptococcus pneumoniae. Eur $J$ Clin Microbiol Infect Dis 1997; 16: 622-623.

5. Pan X-S, Ambler J, Mehtar S, Fisher LM. Involvement of topoisomerase IV and DNA gyrase as ciprofloxacin targets in Streptococcus pneumoniae. Antimicrob Agents Chemother 1996; 40: 2321-2326.

6. Muñoz R, De La Campa AG. ParC subunit of DNA topoisomerase IV of Streptococcus pneumoniae is a primary target of fluoroquinolones and cooperates with DNA gyrase A subunit in forming resistance phenotype. Antimicrob Agents Chemother 1996; 40: 2252-2257.

7. Janoir C, Zeller V, Kitzis M-D, Moreau NJ, Gutmann L. Highlevel fluoroquinolone resistance in Streptococcus pneumoniae requires mutations in parC and gyrA. Antimicrob Agents Chemother 1996; 40: 2760-2764.

8. Pan X-S, Fisher LM. Targeting of DNA gyrase in Streptococcus pneumoniae by sparfloxacin: selective targeting of gyrase or topoisomerase IV by quinolones. Antimicrob Agents Chemother 1997; 41: 471-474.

9. Brenwald NP, Gill MJ, Wise R. The effect of reserpine, an inhibitor of multi-drug efflux pumps, on the in-vitro susceptibilities of fluoroquinolone-resistant strains of Streptococcus pneumoniae to norfloxacin. J Antimicrob Chemother 1997; 40: 458-460.

10. Zeller V, Janoir C, Kitzis M-D, Gutmann L, Moreau NJ. Active efflux as a mechanism of resistance to ciprofloxacin in Streptococcus pneumoniae. Antimicrob Agents Chemother 1997; 41: 1973-1978.

11. Bernard L, Nguyen Van J-C, Mainardi J-L. In vivo selection of Streptococcus pneumoniae resistant to quinolones, including sparfloxacin. Clin Microbiol Infection 1994; 1: 60-61. 